\title{
A case review to describe variation in care following diagnosis of Perthes' disease
}

\section{A. M. Galloway, C. Holton, V. Parnami, M. Wood, J. Craven, N. Green, H. J. Siddle, S. Richards, C. Comer}

From Leeds Children's Hospital and University of Leeds (Leeds Institute of Rheumatic and Musculoskeletal Medicine), Leeds, UK

\section{Aims}

Perthes' disease is a condition which leads to necrosis of the femoral head. It is most commonly reported in children aged four to nine years, with recent statistics suggesting it affects around five per 100,000 children in the UK. Current treatment for the condition aims to maintain the best possible environment for the disease process to run its natural course. Management typically includes physiotherapy with or without surgical intervention. Physiotherapy intervention often will include strengthening/stretching programmes, exercise/ activity advice, and, in some centres, will include intervention, such as hydrotherapy. There is significant variation in care with no consensus on which treatment option is best. The importance of work in this area has been demonstrated by the British Society for Children's Orthopaedic Surgery through the James Lind Alliance's prioritization of work to determine/ identify surgical versus non-surgical management of Perthes' disease. It was identified as the fourth-highest priority for paediatric lower limb surgery research in 2018.

\section{Methods}

Five UK NHS centres, including those from the NEWS (North, East, West and South Yorkshire) orthopaedic group, contributed to this case review, with each entre providing clinical data from a minimum of five children. Information regarding both orthopaedic and physiotherapeutic management over a two-year post-diagnosis period was reviewed.

\section{Results}

Data were extracted from the clinical records of 32 children diagnosed with Perthes' disease; seven boys and 25 girls. The mean age of the children at diagnosis was 6.16 years (standard deviation (SD) 3.001). In all, 26 children were referred for physiotherapy. In the two-year period following diagnosis, children were seen a median of 7.5 times (interquartile range (IQR) 4.25 to 11) by an orthopaedic surgeon, and a median of 9.5 times (IQR 8 to 18.25) by a physiotherapist. One centre had operated on all of their children, while another had operated on none. Overall, 17 (53\%) of the children were managed conservatively in the two-year follow-up period, and 15 (47\%) of the children underwent surgery in the two-year follow-up period.

\section{Conclusion}

The results of this case review demonstrate a variation of care provided to children in the UK with Perthes' disease. Further national and international understanding of current care is required to underpin the rationale for different treatment options in children with Perthes' disease.

Cite this article: Bone Joint Open 2020;1-11:691-695.

Keywords: paediatrics, paediatric orthopaedics, Perthes' disease, Legg-Calve-Perthes, physiotherapy

Correspondence should be sent to Adam M Galloway; email: adamgalloway@nhs.net

doi: 10.1302/2633-1462.111.BJO2020-0139.R1

Bone Joint Open 2020;1-11:691695.

\section{Introduction}

Perthes' disease, a condition which leads to necrosis of the femoral head, was first described in 1910 by Georg Perthes', Arthur Legg, and Jacques Calvé. For this reason, the condition has many names, such as LeggCalvé-Perthes', Legg-Perthes', and CalvéPerthes' to name a few. ${ }^{1}$ Perthes' disease more commonly affects children aged four to nine years, with the most recent statistics 
suggesting it affected five per 100,000 children born in the UK in $2010 .^{2}$ It is almost four-times more likely to affect boys than girls. ${ }^{3,4}$ The condition typically leads to deformation of the femoral head and in turn disturbance in the child's gait. This can restrict activity and prevent participation in physical activity. ${ }^{5}$ This disease has a consistently described pathophysiology in which femoral head necrosis is followed by reabsorption of damaged bone, generation of new bone, and healing of the new bone. ${ }^{6}$ Unfortunately, by this stage some children may have developed complications such as muscle shortening or bony changes with severe gait abnormality. These changes may be severe enough to warrant surgical intervention. When bony damage is severe, total arthroplasty of the hip joint may be warranted, although such extreme surgical intervention is rare. ${ }^{7}$

Currently, management of Perthes' disease is not aimed at altering the aetiology of the disease, but rather at maintaining the best possible environment for the anticipated joint changes. ${ }^{8}$ Treatment options range from 'watchful waiting' to surgical treatment. Surgical options include containment surgery to maintain the position of the femoral head in the acetabulum, ${ }^{9}$ often combined with postoperative physiotherapy for strengthening/stretching. Other treatments include analgesic medication, or active observation, in which the child will be kept under review by orthopaedic surgeons with regular assessment of pain, walking ability, range of movement, and radiological examinations. ${ }^{10}$ Treatments can be combined with physiotherapy to try and maintain range of movement and strength at the hip. The aim is to ensure any skeletal changes do not result in muscle length discrepancies that can lead to adverse outcomes once the disease process is complete and the femur is fully healed, or skeletal maturity has been reached, at which point any further intervention can be considered. ${ }^{10}$

Other proposed treatment options include weightbearing reduction through walking aids, modification of the child's activities, such as restricting high-impact/ load-bearing exercises, and orthotic management, among others. ${ }^{11}$ Currently there is a lack of strong evidence to support any of these treatment options in place of another. Anecdotally, there is also a lack of agreement among clinicians both surgically and nonsurgically about the most effective way to manage children diagnosed with Perthes' disease. The current absence of a standardized evidence-based management approach is not only likely to result in inefficient use of healthcare resources, but also to increase the risk of children receiving inappropriate treatments.

The aim of this case review is to describe current care provided to children with Perthes' disease. The importance of work in this area has been demonstrated by the British Society for Children's Orthopaedic Surgery (BSCOS) through the James Lind Alliance's prioritization of work to 'determine/identify surgical versus nonsurgical management of Perthes' disease', placing it as the fourth-highest priority for paediatric lower limb surgery research in $2018 .^{12}$

\section{Methods}

Five UK NHS centres, including those from the NEWS (North, East, West and South Yorkshire) group, contributed to this case review. Centres from the NEWS Group included the Leeds Children's Hospital, Hull University Teaching Hospitals NHS Trust, and Sheffield Children's Hospital, as well as the Royal Manchester Children's Hospital and Alder Hey Children's Hospital. At each of the centres, a representative of the paediatric orthopaedic team extracted the information required from care records for a minimum of five children diagnosed with Perthes' disease. Each centre had their own patient database; however, a standard operating procedure was produced to ensure a consistent method of identifying children for the case review and for the data extraction in each centre.

After piloting this data extraction procedure in a single site (centre 1), each participating centre was instructed in the standard operating procedure. Data were extracted from consecutive case records for children diagnosed with Perthes' disease. The data encompassed all surgical and non-surgical management documented during the two years following diagnosis of Perthes' disease.

The following data were extracted to describe the care provided:

- Number of consultations the child had with an orthopaedic surgeon.

- Surgery and description of the procedure.

- Pain relief advised by the orthopaedic surgeon.

- Activity modification and description of activity modification suggested by the orthopaedic surgeon.

- Physiotherapy intervention and number of sessions.

Initially, data were extracted from the clinical records of five children from centre 1 to confirm the method of data collection was feasible and produced the required data. Data were extracted from a further five children's care records by a second data collector at centre 1 to ensure the proposed method was feasible and efficient for other centres to collect comparable data. All data were collected in line with the local NHS trust's audit policy and managed by an identified representative from each centre. All patient information was anonymized within their local centre before being collated. The data were summarized using descriptive 
Table I. Characteristics of patients in the case review.

\begin{tabular}{|c|c|c|c|c|c|c|}
\hline Characteristic & Total population & Centre 1 & Centre 2 & Centre 3 & Centre 4 & Centre 5 \\
\hline Patients, $\mathrm{n}$ & 32 & 10 & 7 & 5 & 5 & 5 \\
\hline Female, n (\%) & $7(22)$ & $1(10)$ & $2(29)$ & $2(40)$ & $0(0)$ & $2(40)$ \\
\hline Male, n (\%) & $25(78)$ & $9(90)$ & $5(71)$ & $3(60)$ & $5(100)$ & $3(60)$ \\
\hline Age at diagnosis, yrs, mean (SD) & $6.16(3.001)$ & $7.5(3.61)$ & $4.43(1.71)$ & $6.4(3.51)$ & $5.6(1.95)$ & $5.8(2.17)$ \\
\hline $\begin{array}{l}\text { Number of orthopaedic reviews, median } \\
\text { (IQR for total population) }\end{array}$ & 7.5 (4.25 to 11$)$ & 5 & 9 & 11 & 16 & 4 \\
\hline $\begin{array}{l}\text { Patients provided with pain relief advice, } \\
\mathrm{n}(\%)\end{array}$ & $12(37)$ & $2(20)$ & $2(29)$ & $5(100)$ & $2(29)$ & $1(20)$ \\
\hline $\begin{array}{l}\text { Patients where activity modification } \\
\text { advised, n (\%) }\end{array}$ & $18(56)$ & $5(50)$ & $6(86)$ & $0(0)$ & $5(100)$ & $1(20)$ \\
\hline Physiotherapy in acute setting, n (\%) & $15(58)$ & $3(60)$ & $1(14)$ & $5(100)$ & $0(0)$ & $5(100)$ \\
\hline Physiotherapy in community setting, $\mathrm{n}$ (\%) & $11(42)$ & $2(40)$ & $5(86)$ & $0(0)$ & $5(100)$ & $0(0)$ \\
\hline $\begin{array}{l}\text { Total number of patients referred to } \\
\text { physiotherapy, } \mathrm{n}(\%)\end{array}$ & $26(81)$ & $5(50)$ & $6(86)$ & $5(100)$ & $5(100)$ & $5(100)$ \\
\hline $\begin{array}{l}\text { Number of physiotherapy reviews, nedian } \\
\text { (IQR for total population) }\end{array}$ & 9.5 (8 to 18.25$)$ & 9 & 14 & 8 & 8 & 13 \\
\hline $\begin{array}{l}\text { Patients received surgical intervention, } \mathrm{n} \\
(\%)\end{array}$ & $15(47)$ & $3(30)$ & $4(57)$ & $5(100)$ & $3(60)$ & $0(0)$ \\
\hline $\begin{array}{l}\text { Average time from diagnosis to surgery, } \\
\text { mnths, median (IQR) }\end{array}$ & $4(2$ to 16$)$ & $3(\mathrm{~N} / \mathrm{A})$ & $4(2.25$ to 13.25$)$ & $3(1$ to 11$)$ & $20(N / A)$ & $\mathrm{N} / \mathrm{A}$ \\
\hline $\begin{array}{l}\text { Average age at time of surgery, yrs, median } \\
\text { (IQR) }\end{array}$ & $8(6$ to 10$)$ & $10(\mathrm{~N} / \mathrm{A})$ & $8(5.5$ to 12$)$ & $6(5$ to 10.5$)$ & $9(\mathrm{~N} / \mathrm{A})$ & $\mathrm{N} / \mathrm{A}$ \\
\hline
\end{tabular}

$\mathrm{IQR}$, interquartile range; SD, standard deviation.

statistics to explore patterns and variation in the care provided across the centres.

\section{Results}

Data were extracted from the care records of 32 children diagnosed with Perthes' disease from five centres. The results of the review are provided in Table I.

Children were seen a median of 7.5 times (interquartile range (IQR) 4.25 to 11 ) by an orthopaedic surgeon. Visual inspection of the descriptive data identified variation in practice across centres regarding the number of surgical consultations. For example, centre 1 saw children a median of five times while the children in centre four were seen a median of 16 times.

Pain relief advice was given to $12(37 \%)$ children with a range of specific medications advised/prescribed, including paracetamol, ibuprofen and in one case diclofenac. Pain relief advice was documented for all children seen at centre 3 , but was only documented in a small number of cases at other centres.

When considering activity modification, there were some common themes/activities that were suggested and some that were commonly advised against. For example, one child was told to try swimming to reduce weightbearing on the hip joint. The common activity modification advice was reduction or avoidance of 'high-impact activities'; this was recorded in the clinic letters of 11 children in this case review. Advising against activities such as football, rugby, trampolining, and using a scooter was recorded in multiple clinic letters. On two occasions, children were told to stop all physical activity for one month.

Over $80 \%$ of the children were referred for physiotherapy, with three of the five centres referring all of the children. Physiotherapy intervention was typically delivered in both acute and community settings; some centres provided intervention in a mixture of both settings (centres 1 and 2), while others were wholly seen in one setting (centres 3,4, and 5). Children were seen for a median of 9.5 times (IQR 8 to 18.25) by a physiotherapist during the two-year period following diagnosis.

Almost half $(15 / 32)$ of the children had hip surgery during the first two years following diagnosis. The most common surgical procedure was a varus osteotomy, followed by adductor tenotomy. One centre reported that surgical intervention was undertaken in all five children (centre 3) compared to another (centre 5) that did not report any surgical interventions in the first two years following diagnosis. Surgical intervention was conducted within the first four months, with the exception of centre 4 which had a much longer average time from diagnosis to surgery (20 months).

\section{Discussion}

This case review outlines the significant variation in care children with Perthes' disease received in the first two years following diagnosis across five orthopaedic centres. Most notably, there is variation in frequency and type of surgical interventions across centres, and a 
wide variation in the type and amount of non-surgical treatment received.

In 2007, a survey was completed at a British Society of Children's Orthopaedic Surgery (BSCOS) meeting to assess the variation of care regarding surgery in the UK, and described a large variability in the treatment chosen for children with Perthes' disease. ${ }^{13}$ The results of our case review 12 years later remain consistent with these survey findings, and further highlight the need for evidence and consensus in managing this disease.

In 2009, Herring et $\mathrm{al}^{14}$ carried out a prospective multicentre study looking at different interventions, and reported no benefit from the non-surgical interventions provided in their trial of bracing and range of movement exercises compared with no treatment. There was also no significant difference when comparing different surgical procedures meaning there remains to be any conclusive evidence for surgical effectiveness. ${ }^{15}$ Recent years have seen little additional research to add to this limited evidence. As a result, there is currently insufficient evidence from clinical trials to inform surgical decisions and candidacy. Finally, there is a lack of evidence regarding the effectiveness of non-surgical interventions, including physiotherapy as an alternative to surgery. As a result, care is varied and may be suboptimal.

More evidence is needed to develop and test the most effective method of non-surgical management for Perthes' disease in children. Additionally, evidence to underpin the appropriate identification of potential surgical candidates who are unlikely to do well with non-surgical management is required. Such insight might reduce the risk of exposure to potentially unnecessary interventions and inform more efficient use of healthcare resources in the management of Perthes' disease.

Limitations of this case series include the geographical restriction of the cases reviewed. Perthes' disease is a worldwide condition, and therefore the surgical and non-surgical management of the cases reviewed may not be representative of or reflect the needs or treatment opportunities of children in other regions or countries. ${ }^{2,16} \mathrm{~A}$ second limitation is the restricted amount of information gathered. Collection of more information might have provided greater insight into current management, such as why the child was listed for surgery, determining what non-surgical interventions were undertaken, and the clinical decisions underpinning treatment choices and interventions, such as physiotherapy and advice given. A longer follow-up time might also have provided some additional insight. However, this case review has provided a clear indication of the wide variation in current management of Perthes' disease, which will inform future work in this field. Future work will include exploratory work to gain an understanding of what clinicians, surgeons, children, and their families believe should be done and what is best for children with Perthes' disease.

In conclusion, the current literature on clinical management of Perthes' disease provides little evidence to guide selection of effective treatment. Our case review reflects the consequent variability in clinical practice by showing the differences in the care received by children with Perthes' disease in a select number of centres in the UK during their first two years following diagnosis. Further research is needed to bridge the gap in knowledge and to inform effective management of children with Perthes' disease.

\section{Take home message}

- The current literature on clinical management of Perthes' disease provides little evidence to guide selection of effective treatment.

- This case review demonstrates the variability in treatment for children with Perthes' disease.

- Further research is needed to bridge the gap in knowledge and to

inform effective management of children with Perthes' disease.

\section{Twitter}

Follow A. M. Galloway @GallowayAdam

Follow C. Holton @ HoltonColin

Follow H. J. Siddle @HeidiSiddle

Follow S. Richards @RichaSuzy

Follow C. Comer @DrCComer

\section{References}

1. Perry DC. Unravelling the enigma of Perthes disease. Ann R Coll Surg Engl. 2013;95(5):311-316.

2. Perry DC, Bruce CE, Pope D, Dangerfield P, Platt MJ, Hall AJ. Legg-CalvéPerthes disease in the UK: geographic and temporal trends in incidence reflecting differences in degree of deprivation in childhood. Arthritis \& Rheumatism. 2012;64(5):1673-1679.

3. Margetts BM, Perry CA, Taylor JF, Dangerfield PH. The incidence and distribution of Legg-Calvé-Perthes' disease in Liverpool, 1982-95. Arch Dis Child. 2001;84(4):351-354.

4. Loder RT, Skopelja EN. Loder RT, Skopelja EN. The epidemiology and demographics of Legg-Calvé-Perthes' disease. ISRN Orthop. 2011;2011(1):1-14.

5. Kim HKW. Legg-Calvé-Perthes disease. J Am Acad Orthop Surg. 2010;18(11):676-686.

6. Stulberg SD, Cooperman DR, Wallensten $\mathbf{R}$. The natural history of Legg-CalvéPerthes disease. J Bone Joint Surg Am. 1981;63(7):1095-1108.

7. Joseph B, Nair NS, Narasimha Rao KL, Mulpuri K, Varghese G. Optimal timing for containment surgery for Perthes disease. J Pediatr Orthop. 2003;23(5):601-606.

8. Manig M. Legg-Calvé-Perthes disease (LCPD). Principles of diagnosis and treatment. Orthopade. 2013:42(10):891-904.

9. Price CT, Thompson GH, Wenger DR. Containment methods for treatment of Legg-Calvé-Perthes disease. Orthop Clin North Am. 2011;42(3):329-340.

10. Brech GC, Guarnieiro R. Evaluation of physiotherapy in the treatment of LeggCalvé-Perthes disease. Clinics. 2006;61(6):521-528.

11. Rich MM, Schoenecker PL. Management of Legg-Calvé-Perthes disease using an A-Frame orthosis and hip range of motion. J Pediatr Orthop. 2013;33(2):112-119.

12. James Lind Alliance. Priority 4 from the paediatric lower limb surgery PSP. 2019. http://www.jla.nihr.ac.uk/priority-setting-partnerships/Paediatric-lowerlimb-surgery/priority-4-from-the-paediatric-lower-limb-surgery-psp.htm (date last accessed 27 October 2020).

13. Annamalai SKM, Buckingham R, Cashman J. Perthes disease: a survey of management amongst members of the British Society for children's orthopaedic surgery (BSCOS). J Child Orthop. 2007;1(2):107-113.

14. Herring JA, Kim HT, Browne R. Legg-Calve-Perthes disease. Part II: prospective multicenter study of the effect of treatment on outcome. J Bone Joint Surg Am. 2004;86(10):2121-2134 
15. Moberg A Hansson G Kaniklides C. Results after femoral and innominate osteotomy in Legg-Calvé-Perthes disease. Clin Orthop Relat Res. 1997;334:257-264.

16. Sharma S, Sibinski M, Sherlock DA. A profile of Perthes' disease in greater Glasgow: is there an association with deprivation? J Bone Joint Surg Br. 2005:87(11):1536-1540.

\section{Author information:}

A. M. Galloway, MSc, BSc (Hons), MCSP, Senior Children's Physiotherapist and NIHR/ ICA Pre-doctoral Clinical Academic Fellow, Leeds Teaching Hospitals NHS Trust and University of Leeds, Leeds, UK.

- C. Holton, MSc (Mech Eng), BSc (Anatomy Hons), MBChB, FRCS (Tr \& Orth), Consultant Orthopaedic Surgeon, Leeds Teaching Hospitals NHS Trust, Leeds, UK.

v. Parnami, MBBS, D Ortho, DNB Ortho, MRCS, Orthopaedic trainee, Royal Manchester Children's Hospital, Manchester, UK.

- M. Wood, BSc (Hons), MCSP, Specialist Children's Physiotherapist, Hull University Teaching Hospitals NHS Trust, Hull, UK.

- J. Craven, MBBS, Orthopaedic Trainee, Alder Hey Children's Hospital NHS Foundation Trust, Liverpool, UK.

n N. Green, MSc (Trauma), Cert (ESSQ) MBChB, FRCS (Tr \& Orth), Orthopaedic Trainee, Sheffield Children's Hospital, Sheffield, UK.

- H. J. Siddle, PhD, Consultant Podiatrist and Associate Professor

- C. Comer, PhD, Extended Scope Practictioner Physiotherapist and Associate Professo Leeds Institute of Rheumatic and Musculoskeletal Medicine, University of Leeds, Leeds, UK.

S. Richards, PhD, Professor, Professor of Primary Care Research, Institute of Health Science, University of Leeds, Leeds, UK.
Author contributions:

A. M. Galloway: Designed the studty, Collected and analyzed the data, Edited the manuscript.

- C. Holton: Designed the study, Collected the data, Edited the manuscript.

V. Parnami: Collected the data, Edited the manuscript.

M. Wood: Collected the data, Edited the manuscript.

- J. Craven: Collected the data, Edited the manuscript.

N. Green: Collected the data, Edited the manuscript.

H. J. Siddle: Designed the study, Collected and analyzed the data, Edited the manuscript.

S. Richards: Designed the study, Collected and analyzed the data, Edited the manuscript.

C. Comer: Designed the study, Collected and analyzed the data, Edited the manuscript.

Funding statement:

No benefits in any form have been received or will be received from a commercial party related directly or indirectly to the subject of this article.

ICMJE COI statement:

Adam Galloway is funded by a National Institute for Health Research (NIHR) and Health Education England (HEE) Pre-doctoral Clinical Academic Fellowship. The views expressed are those of the author(s) and not necessarily those of the NIHR or the Department of Health and Social Care.

Acknowledgements

Many thanks to the included NHS Trusts for their participation in this piece of work.

(c) 2020 Author(s) et al. This is an open-access article distributed under the terms of the Creative Commons Attribution Non-Commercial No Derivatives (CC BY-NC-ND 4.0) licence, which permits the copying and redistribution of the work only, and provided the original author and source are credited. See https://creativecommons.org/licenses/ by-nc-nd/4.0/ 